\title{
Potential function of CbuSPL and gene encoding its interacting protein during flowering in Catalpa bungei
}

\author{
Zhi Wang ${ }^{1}$, Tianqing Zhu', Wenjun Ma', Erqin Fan ${ }^{1,3}$, Nan Lu', Fangqun Ouyang ${ }^{1}$, Nan Wang ${ }^{1}$, Guijuan Yang ${ }^{1}$, \\ Lisheng Kong ${ }^{2}$, Guanzheng Qu ${ }^{3}$, Shougong Zhang ${ }^{1}$ and Junhui Wang ${ }^{1 *}$
}

\begin{abstract}
Background: "Bairihua", a variety of the Catalpa bungei, has a large amount of flowers and a long flowering period which make it an excellent material for flowering researches in trees. SPL is one of the hub genes that regulate both flowering transition and development.

Results: SPL homologues CbuSPL9 was cloned using degenerate primers with RACE. Expression studies during flowering transition in "Bairihua" and ectopic expression in Arabidopsis showed that CbuSPL9 was functional similarly with its Arabidopsis homologues. In the next step, we used $\mathrm{Y} 2 \mathrm{H}$ to identify the proteins that could interact with CbuSPL9. HMGA, an architectural transcriptional factor, was identified and cloned for further research. BiFC and BLI showed that CbuSPL9 could form a heterodimer with CbuHMGA in the nucleus. The expression analysis showed that CbuHMGA had a similar expression trend to that of CbuSPL9 during flowering in "Bairihua". Intriguingly, ectopic expression of CbuHMGA in Arabidopsis would lead to aberrant flowers, but did not effect flowering time.

Conclusions: Our results implied a novel pathway that CbuSPL9 regulated flowering development, but not flowering transition, with the participation of CbuHMGA. Further investments need to be done to verify the details of this pathway.
\end{abstract}

Keywords: Catalpa bungei, Flowering, SPL, HMGA, Architectural transcriptional factor

\section{Background}

Flowers allow flowering plants to have a broader evolutionary relationship and extend their ecological niche so that they can dominate the terrestrial ecosystem. Flowering is extremely important for the development of perennial woody plants and for improving the economic value of plants. However, due to complex genomes and other objective characteristics of perennial woody plants, research on the flowering

\footnotetext{
* Correspondence: wangjh808@sina.com

'Present address: State Key Laboratory of Tree Genetics and Breeding, Key Laboratory of Tree Breeding and Cultivation of State Forestry Administration, Research Institute of Forestry, Chinese Academy of Forestry, Beijing 100091, People's Republic of China

Full list of author information is available at the end of the article
}

process in perennial woody plants remains limited. Catalpa bungei is valuable as both a timber and an ornamental tree [1]. "Bairihua", which is a natural variety of C. bungei, has been characterized for its especially short juvenile period, large number of flowers and long flowering period. The flowering period of "Bairihua" is approximately 15 days, and its accumulative flowering period reaches 100 days, which is very rare for woody plants (http://www.forestry.gov.cn/). "Bairihua" provides an excellent opportunity to evaluate the flowering process of woody plants.

Flowering is controlled by sophisticated regulatory networks [2-5]. Five major pathways are involved in these processes, including the aging pathway [6],

C C The Author(s). 2020 Open Access This article is licensed under a Creative Commons Attribution 4.0 International License, which permits use, sharing, adaptation, distribution and reproduction in any medium or format, as long as you give appropriate credit to the original author(s) and the source, provide a link to the Creative Commons licence, and indicate if changes were made. The images or other third party material in this article are included in the article's Creative Commons licence, unless indicated otherwise in a credit line to the material. If material is not included in the article's Creative Commons licence and your intended use is not permitted by statutory regulation or exceeds the permitted use, you will need to obtain permission directly from the copyright holder. To view a copy of this licence, visit http://creativecommons.org/licenses/by/4.0/ The Creative Commons Public Domain Dedication waiver (http://creativecommons.org/publicdomain/zero/1.0/) applies to the data made available in this article, unless otherwise stated in a credit line to the data. 
gibberellin pathway [7-10], photoperiod pathway [1113], vernalization pathway [14-16] and autonomous pathway [17]. The SQUAMOSA promoter-binding protein-LIKE (SPL) family of transcription factors (TFs) integrate multiple pathways [18-22]. SPLs have been shown to regulate flowering time and flower organ development in both herbs and woody plants, such as Gossypium hirsutum [23], maize [24], birch [25], Prunus mume [26], Platanus acerifolia [27], and Populus trichocarpa [28]. In the model plant Arabidopsis, AtSPLs have been shown to be a group of dominant regulators of the flowering process [29-32]. The overexpression of AtSPLs leads to early flowering and abnormal inflorescence, and conversely, the inhibition of AtSPL expression delays the occurrence of floral transition [33-35]. As a group of TFs, SPLs regulate the expression of other genes. Numerous downstream genes of SPLs have been identified; for example, AtSPL3 can directly upregulate the expression of $L F Y, F U L$ and $A P 1$ by binding to their promoters [36-38]. However, in addition to protein-DNA interactions, TFs also affect plant growth and development by forming protein complexes. For example, the MYBbHLH-WD40/WDR (MBW) complex regulates late biosynthetic genes in anthocyanin biosynthesis, impacts fruit quality in apple $[39,40]$, and regulates trichome initiation in Arabidopsis thaliana [41]. Two TFs, ATHOOK MOTIF NUCLEAR LOCALIZED PROTEIN 3/4, regulate the formation of the tissue boundary between the procambium and xylem in Arabidopsis roots [42]. Few studies have investigated whether there are other factors that interact with SPLs and affect their binding ability, especially in trees. The function of SPLs in woody plants is still in its infancy.

In an effort to study the molecular mechanism of the flowering process in "Bairihua", we evaluated whether there were protein interactions involved in SPL regulation during the flowering process. As a first step to address this question, we isolated and characterized the SPL9 orthologous gene from "Bairihua" and performed native in planta gene expression analysis. The putative function of this gene was then tested by ectopic expression experiments. This gene showed similar expression patterns and the ability to induce flower organ development and early flowers in Arabidopsis. The findings of this study indicated that CbuSPL9 is functionally conserved. An architectural TF, CbuHMGA, was found via screening CbuSPL9interacting proteins. CbuHMGA is involved in the floral organ development of "Bairihua", but not in the regulation of flowering time. These results provide a molecular basis for studying the molecular mechanism of "Bairihua" flowering and provide a research direction for the study of the floral transition of perennials.

\section{Methods}

\section{Plant materials}

C. bungei is a perennial tree that typically flowers over a 30-day flowering period. However, "Bairihua", the new variety of $C$. bungei, was found in Henan Province, China, and confirmed by the National Forestry and Grassland Administration (http://www.forestry.gov.cn/). The flowering period of a single flower is approximately 15 days, and its accumulative flowering period reaches 100 days, which is very rare for woody plants. From January 15 to April 2, 2017, we collected the first round of axillary buds of FB and LB varieties. Samples were collected every 10 days during the dormant and germinating periods. Since the floral transition of "Bairihua" was completed within 7 to 10 days, samples were collected every day during the floral transition period, and the samples were collected every 5 days during the reproductive growth stage. The samples used for RNA extraction were washed with distilled water, frozen immediately in liquid nitrogen, and stored at $-80^{\circ} \mathrm{C}$. Samples for histological analysis were fixed in a formalin:glacial acetic acid:70\% ethanol (5:5:90 vol.; FAA) solution under a vacuum for at least $24 \mathrm{~h}$. All the plant material collections in our study were complied with national guidelines. The field experiment we made were in accordance with local legislation. The voucher specimens were deposited in Research Institute of Forestry, Chinese Academy of Forestry. Dr. Wenjun Ma and Dr. Junhui Wang undertook the formal identification of the samples.

\section{Histological analysis}

For histological analysis, the samples were immersed in FAA fixative and placed under vacuum at $4{ }^{\circ} \mathrm{C}$. Samples were dehydrated in gradient ethanol and then embedded in paraffin. Ten-mm-thick sections (RM2255 Fully Automated Rotary Microtome; Leica, Germany) were stained with Safranine $O$ and fast green FCF (Sigma-Aldrich, USA). The slices were observed and photographed using a Leica DM 6000B fully automated upright microscope (Leica Microsystems GmbH, Wetzlar, Germany).

\section{Cloning CbuSPL9 and CbuHMGA sequences from "Bairihua"}

RNA from "Bairihua" was extracted from the buds of the mutant using an RNA extraction kit (TaKaRa), and contaminating DNA was removed with RNase-free DNase I (TaKaRa). One or two micrograms of total mRNA template was added to Oligod (dT)18 primer and reversetranscribed into single-stranded cDNA by M-MLV RTase (TaKaRa). The full-length cDNA of CbuSPL9 was cloned via $3^{\prime}$-RACE and 5'-RACE by using the (TaKaRa) according to the manufacturer's instructions. In 3'-RACE, the CbuSPL9 gene-specific forward primers 
F1/F2 were designed based on published and aligned SPL sequences from NCBI (http://blast.ncbi.nlm.nih.gov/ Blast.cgi). F1 nested immediately upstream of F2. The 3 '-cDNA synthesis primer was provided in a kit. The PCR products were cloned into the PMD18-T vector and sequenced. CbuSPL9s were identified using BLAST. In 5'-RACE, the gene-specific reverse primers R1/R2 (Additional file 1) were designed based on sequences from 3'-RACE. R2 nested immediately upstream of R1. The PCR products were cloned into the PMD18-T vector and sequenced.

\section{Yeast two-hybrid (Y2H) screening of the "Bairihua" cDNA library}

The equal amounts of "Bairihua" buds (Collected the first round of axillary buds of "Bairihua") from each period (Dormant period, Germination period, Floral transition period and Reproductive growth period) were pool together. Total RNA from the "Bairihua" buds from four periods, was mixed to provide the mRNA sample. A yeast library was constructed by Oebiotech (Shanghai, China) via cloning the full-length cDNA library from mRNAs sample into the pGADT7 vector. CbuSPL9 was inserted into the pGBKT7 vector. Screening of the yeast library was performed using pGBKT7-CbuSPL9. The corresponding primers are listed in Additional file 1. Transformed cells were grown on SD medium supplemented with Trp. The transformants were screened on supplemented SD medium lacking Leu, Trp, His and Ade and supplemented with $\mathrm{X}-\mathrm{a}-\mathrm{Gal}$ and Aureobasidin A. Plates were incubated at $30^{\circ} \mathrm{C}$ for $48-72 \mathrm{~h}$ and photographed. The positive clones were verified with both pGBKT7 vector consensus primers. Positive control mating was as follows: pGADT7-T in Y2HGold and pGBK-53 in Y187. Negative control mating was as follows: pGADT7-T in Y2HGold and pGBKT7-Lam in Y187.

\section{Subcellular localization}

To validate subcellular localization, the full-length coding sequences (without the stop codon) of CbuSPL9 and CbuHMGA were amplified from RNA of "Bairihua" buds by RT-PCR. The PCR products of CbuSPL9 and CbuHMGA were ligated to the vector pCAMBIA1304 using the Seamless Assembly Cloning Kit (CloneSmarter, Beijing, China) to construct the CbuSPL9/CbuHMGAGFP fusion genes driven by a CaMV35S promoter. pCAMBIA1304-GFP was used as a positive control. The transient expression vectors CbuSPL9-GFP, CbuHMGAGFP and GFP-HDEL were injected into the leaf lower epidermal cells of Nicotiana tabacum L. using Agrobacterium transformation. The transformed cells were incubated for 2 days. The leaves were removed, cut into squares and immersed in PBS buffer containing $1 \mathrm{~g} \mathrm{~mL}^{-1}$ DAPI to stain the nuclei. The transient expression of the CbuSPL9/
CbuHMGA-GFP fusion proteins was observed under an UltraVIEW VoX 3D Live Cell Imaging System Spinning Disk confocal laser scanning microscope (PerkinElmer, Waltham, MA, USA). The wavelength of excitation used was $488 \mathrm{~nm}$ for GFP and $405 \mathrm{~nm}$ for DAPI.

\section{BiFC analysis}

To confirm and visualize the interaction between CbuSPL9 and CbuHMGA in protoplasts from Populus trichocarpa, a $\mathrm{BiFC}$ assay was performed based on split EYFP. EYFP was fused to the C-terminus of CbuSPL9 and the Nterminus of CbuHMGA, resulting in CbuSPL:EYFP ${ }^{C}$ and CbuHMGA:EYFP ${ }^{\mathrm{N}}$. A positive EYFP signal indicates an interaction of $\mathrm{EYFP}^{\mathrm{C}}$ and $\mathrm{EYFP}^{\mathrm{N}}$ due to the heterodimerization of CbuSPL9 with CbuHMGA. CbuSPL:EYFP ${ }^{C}$ was cotransfected with CbuHMGA:EYFP ${ }^{\mathrm{N}}$ and H2A: mCherry into protoplasts. The transient expression of the CbuSPL9/CbuHMGA-GFP fusion proteins was observed under an UltraVIEW VoX 3D Live Cell Imaging System Spinning Disk confocal laser scanning microscope (PerkinElmer, Waltham, MA, USA).

\section{Biolayer interferometry assay}

CbuSPL9 was cloned into pGEX6P-1 as a C-terminal GST-tagged construct, and the construct was confirmed by sequencing. CbuHMGA was cloned into pET28a as an $\mathrm{N}$-terminal $6 \mathrm{His}$-tagged construct, and the construct was confirmed by sequencing. The protein was purified using the procedure for EMCV-3C and $\mathrm{RV}-3 \mathrm{C}$ as described above. Real-time interactions between CbuHMGA and CbuSPL9 were monitored with an Octet QK (Forte-Bio) that is based on BLI. BLI was used to determine dissociation constants $\left(\mathrm{K}_{\mathrm{D}}\right)$ as well as the on- and off-rate $\left(\mathrm{k}_{\text {on }}\right.$ and $\mathrm{k}_{\text {off }}$ ) for HIS-CbuHMG binding to GST-CbuSPL1.

\section{Bioinformatic analysis}

Multiple sequence alignment and phylogenetic analysis were performed using MEGA6.0. After alignment, the evolutionary history was calculated using the neighborjoining (NJ) method. The tree was inferred from 1000 bootstrap replicates to show the evolutionary history of the genes. The MEME online tool (http://meme-suite. org/tools/meme) was used to identify the motifs of the CbuSPL9 protein. MEME was run locally with the following parameters: number of repetitions = any and maximum number of motifs $=20$. All candidate interacting protein sequences were examined by the domain analysis program SMART (Simple Modular Architecture Research Tool) (http://smart.embl-heidelberg.de/). CbuSPL9 was submitted to the psRNATarget server (http://plantgrn.noble.org/psRNATarget/) with an expectation value $<3$. CbuSPL9 containing no more than four mismatches and $\mathrm{G} / \mathrm{U}$ pairs within the complementary regions were considered miRNA targets. 


\section{RNA extraction and quantitative real-time PCR}

Total RNA was isolated from "Bairihua" buds at different developmental stages. The purity and quality of RNA was checked by NanoDrop8000 (Thermo Fisher Scientific, Waltham, MA, USA) and analyzed by gel electrophoresis. First-strand cDNA synthesis was carried out with $\sim 1 \mu \mathrm{g}$ RNA using the SuperScript III reverse transcription kit (Invitrogen) and random primers according to the manufacturer's instructions. Primers were designed using Primer 3 online. The melting temperature of the primers was $60{ }^{\circ} \mathrm{C}$, and the amplicon lengths were 100-200 bp. All primers are listed in Additional file 1. Real-time qRT-PCR was performed on a Roche LightCycle 480 Real-Time PCR System (Roche Applied Science, Germany) using a SYBR Premix Ex $\mathrm{Taq}^{\mathrm{Tm}} \mathrm{Kit}$ (TaKaRa, Dalian, China) according to the manufacturer's instructions using a $20 \mu \mathrm{l}$ reaction volume $(10 \mu \mathrm{l}$ of $2 \times$ SYBR Premix, $2 \mu \mathrm{l}$ of cDNA templates as prepared above and $1 \mu \mathrm{l}$ of each specific primer to a final concentration of $200 \mathrm{nM}$ ) [43]. Relative expression levels were calculated using the $2^{-\Delta \Delta C t}$ method. Actin was used as an internal control, and each reaction was conducted in triplicate [1]. The stem expression values were set to 1. U6 were amplified as an endogenous control [44]. All the primers are shown in Additional file 1. We test the correlation of expression (CEG) between CbuSPL9/miR156 by using the Pearson correlation coefficient. The Pearson correlation coefficient was calculated by $\operatorname{COR}()$ using average relative expressions of three replicates in $\mathrm{R}$. A Pearson correlation is a number between -1 and 1 . 0 represents no correlation, negative value is negative correlation, positive value is positive correlation [45].

\section{Transient overexpression in Arabidopsis thaliana}

Full-length CbuSPL9 and CbuHMGA were cloned into the binary vector pBI121 (BD Biosciences Clontech, USA) under the control of the cauliflower mosaic virus $35 \mathrm{~S}$ promoter in the sense orientation. The transgenic plants were generated with the 35S:CbuSPL9 and 35S: CbuHMGA constructs via Agrobacterium tumefaciens GV3101 by using the floral dip method. Surfacesterilized T1 seeds were grown on a solid $0.5 \times \mathrm{MS}$ medium containing $30 \mu \mathrm{g} \mathrm{mL}^{-1}$ hygromycin at $4{ }^{\circ} \mathrm{C}$ for 2 days, which were then transferred to the greenhouse under long-day conditions ( $16 \mathrm{~h}$ light/8 h dark) at $22^{\circ} \mathrm{C}$ for 10 days. Subsequently, the seedlings were transplanted into soil. Phenotypes of the transgenic plants were observed in the T1 generation, and the overexpression of CbuSPL9 and CbuHMGA in the transgenic plants was confirmed by PCR genotyping (Additional files 2 and 3). For each construct, at least 10 transgenic lines with similar phenotypes were observed, and 3 of them were used for detailed analysis [1].

\section{Flowering time measurement}

Plants were grown on soil in the greenhouse under longday condition $\left(16 \mathrm{~h}\right.$ light $/ 8 \mathrm{~h}$ dark) at $22^{\circ} \mathrm{C}$. Flowering time was measured by counting the total number of rosette leaves and the number of days (from sowing to floral bud formation). The numbers of rosette leaves of $\sim 20$ plants were counted and averaged. Data were classified with Win-Excel and analyzed via analysis of variance (ANOVA) using the SPSS (version 8.0, SPSS Inc., Chicago, IL, USA) statistical package. Comparisons between the treatment means were made using Tukey's test at a probability level of $P<=0.05[46,47]$.

\section{Results}

\section{A flowering-related CDNA of SPL was cloning from "Bairihua"}

Full-length cDNAs of SPL from C. bungei were isolated by using homology-based cloning and RACE techniques. The isolated conserved sequences were extended by genome walking to acquire the full genomic sequences (exons and introns). One of the isolated sequences encoded a protein with a typical SPL protein structure, which included a highly conserved SBP-box domain bearing two zinc-binding sites and one bipartite nuclear localization signal $[6,19,48]$ (Additional file 4). The first $\mathrm{Zn}$-finger-like structure (ZN-1 in Fig. 1a) was C3H-type, and the second ( $\mathrm{Zn}-2$ in Fig. 1a) was C2HC-type. The nuclear localization sequence (NLS) is a highly conserved bipartite domain located at the C-terminus of SBP. Phylogenetic analysis showed that the isolated sequence clustered with AtSPL9 and AtSPL15 (Fig. 1b). Since it shared more sequence similarity with AtSPL9, we named the SPL homologous gene CbuSPL9. And CbuSPL9 was predicted to be a target of miR156 (Additional file 5), which is consistent with previous reports of $S P L$ in Arabidopsis involving in flowering process .

\section{Expression of CbuSPL9 during the flowering process}

Intensive sampling was performed to investigate the changes in CbuSPL9 expression during the flowering process (Fig. 2). The determination of T1-T3 is based on the phenological of "Bairihua", the current state of the buds, and the morphology of the apical meristem. The buds in T1-T3 peroids is covered with a thick layer of hard bud scales, and its morphology has no significant differences to observed between the flowering buds (FBs) and the leaf buds (LBs). T4-T5 was the germination period. The germinating period of "Bairihua" generally begins in early march, when the buds gradually strip off the hard bud scale, and reveals the soft reddish brown tip.

During this period, the internal morphology was similar between the FBs and LBs. T6-T9 followed the short germination period and was the floral transition period, 
a

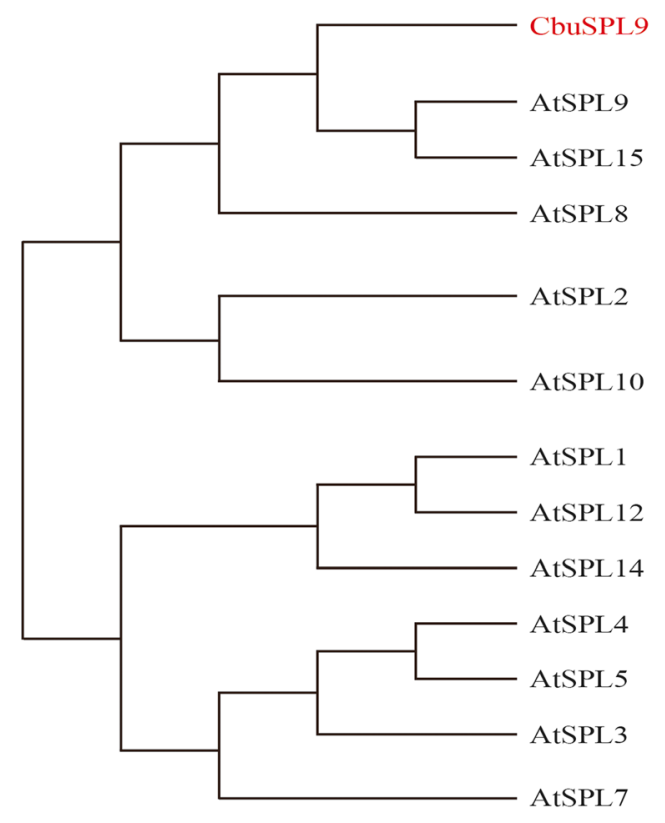

b
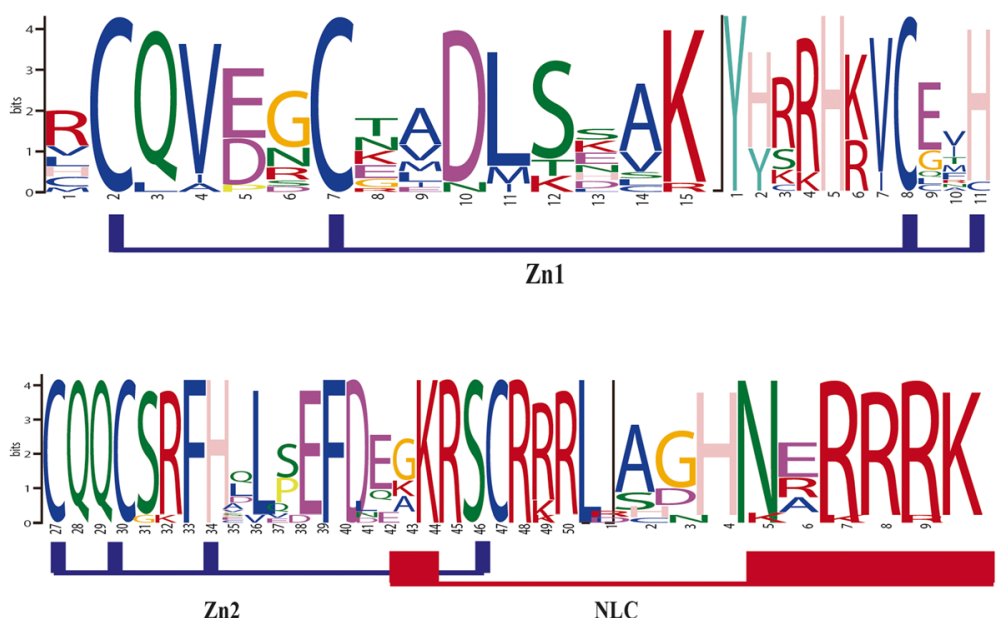

Fig. 1 The phylogenetic relationship and motif composition analysis of the CbuSPL9 gene in C. bungei. a Multiple sequence alignment and sequence logo of the C. bungei SBP-box domain. Sequence alignment was performed with DNAMAN. The two conserved zinc fingers and NLS are indicated. The sequence logo was obtained from MEME online software. The overall height of the stack indicates the sequence conservation at that position. b The phylogenetic tree was constructed with MEGA 6.0 by the neighbor-joining (NJ) method with 1000 bootstrap replicates. Bootstrap support is indicated at each node. A. thaliana (At), C. bungei (Cbu)

during which flower primordium and leaf primordium were developed in the FBs and LBs, respectively. Finally, T10-T12 was the reproductive growth period. The expression level of CbuSPL9 was significantly higher in the FBs than in the LBs, especially during the dormant period and the reproductive growth period. The classical model related flowering governed by microRNA 156 (miR156) and its targeted SPLs [35, 49, 50]. During flowering process of "Bairihua", the expression levels of miR156 was significantly higher in the LBs than in the
FBs, and gradually decrease with age. Based on the overall trend, CbuSPL9 and miR156 exhibited negative correlations with $r<-0.8$ (Additional file 6). Much higher levels of expression in FBs compared to LBs during T6T12 periods was observed for AtSPL homologous target genes. The results showed that CbuAP1 and CbuLeafy are positive correlation with CbuSPL9 from T6 period to T12 period in FBs (Additional file 7). Overall, the expression study supported that CbuSPL9 was an SPL homologous gene and involved in flowering regulation. 


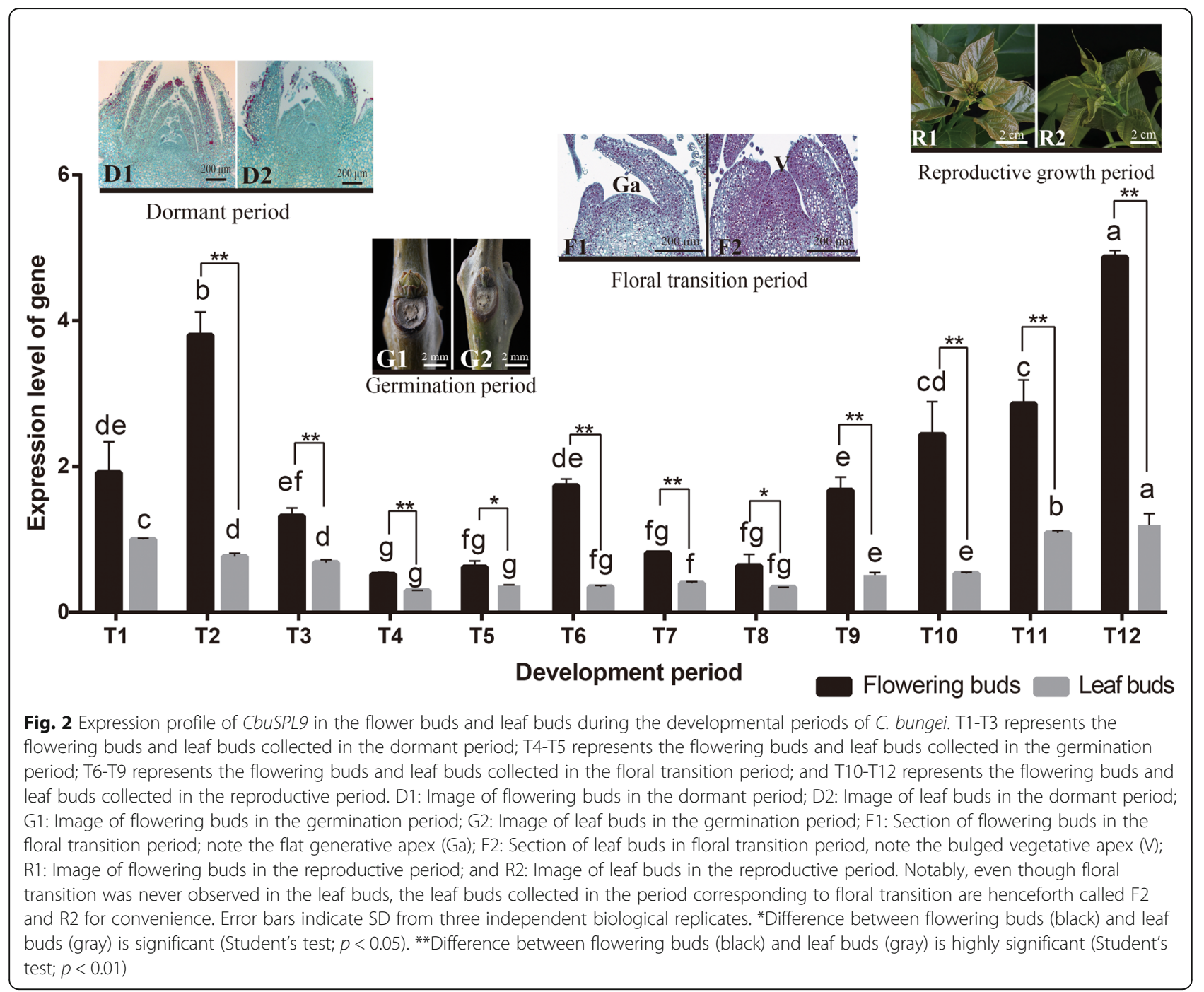

The overexpression of CbuSPL9 in Arabidopsis

As there is no available transformation system in C. bungei, CbuSPL9 was overexpressed in Arabidopsis (Columbia ecotype, col). The flowers from col were tetradynamous and had four petals distributed in cross type (Fig. 3aI). In contrast, the oe-spl9 transgenic plants showed aberrant flower organs (Additional file 8). The oe-spl9 transgenic lines exhibited flower organs with altered numbers and locations, such as shrunken petals, increased stamens, and overlapping petals (Fig. 3aII-VI). In addition to the evident changes in floral organ morphology, an acceleration in flowering time was observed in the oe-spl9 lines (Fig. 3b, Additional file 9). The col line initiated flowering when 14 rosette leaves were present (Fig. 3c). However, oe-spl9 possessed less than 9 rosette leaves at the time of bolting (Fig. 3d). This result indicated that the function of CbuSPL9 was conserved. The regulatory mechanism of CbuSPL9 in "Bairihua" might be similar to that in Arabidopsis.

\section{Screening CbuSPL9-interacting proteins}

As a TF, SPL-DNA interaction studies have been extensively performed. However, TFs can also fine-tune specific biological processes through protein interactions. We constructed a C. bungei yeast two-hybrid cDNA library to explore the proteins that interact with CbuSPL9. A total of 809 blue colonies representing potential positive clones were obtained on QDO/ $\mathrm{Aba} / \mathrm{X}-\mathrm{a}-\mathrm{Gal}$ plates. The potential positive clones were subsequently tested by PCR for the library plasmid, and 406 clones were positive. The resulting PCR products were sequenced, and the sequences were aligned using the NCBI BLASTp search function. Finally, 12 interacting protein candidates were identified (Table 1). These predicted proteins included HMGA, aquaporins, bHLH48, GATA-related protein, PHD finger protein ALFIN-LIKE 4, heavy metalassociated protein, etc. 


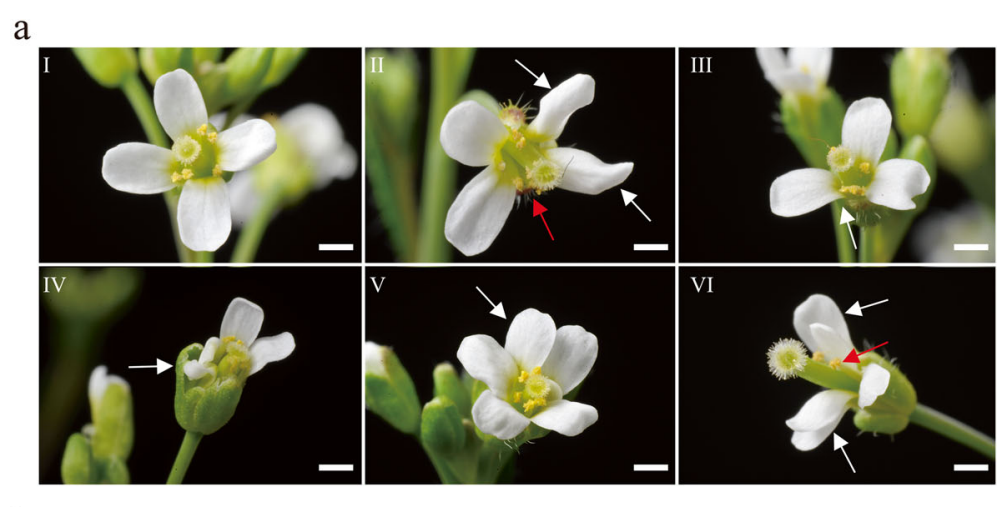

b
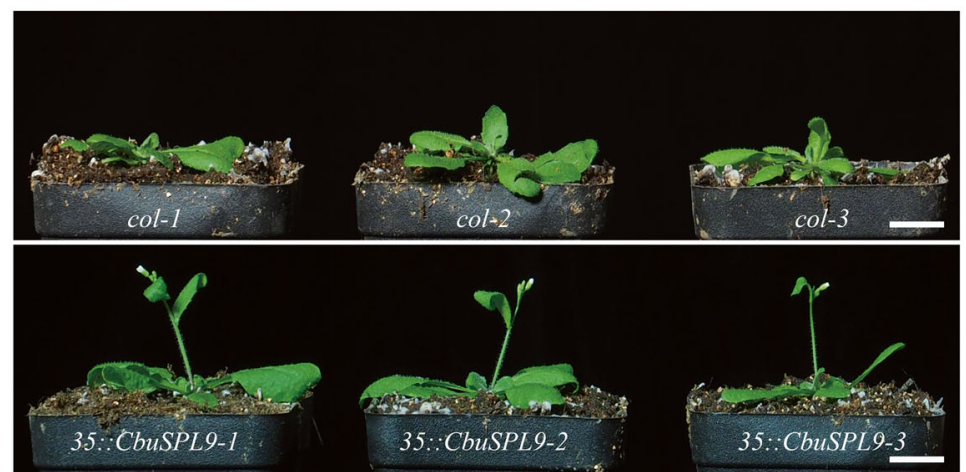

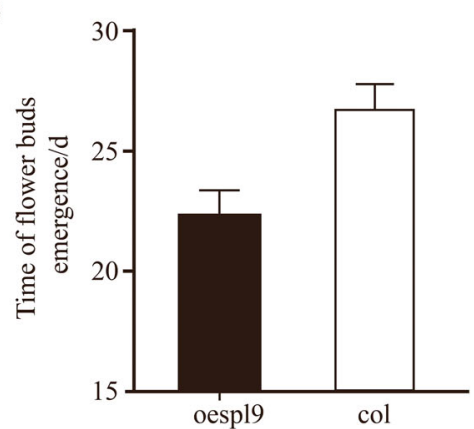

d

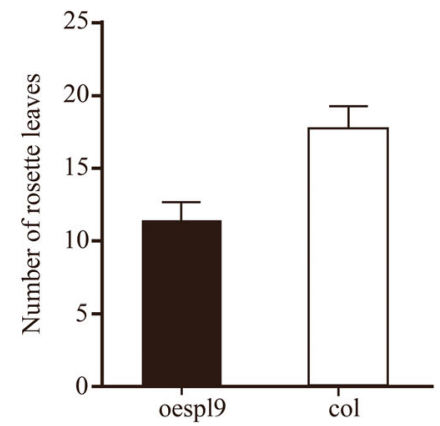

Fig. 3 Phenotype of overexpression mutants of CbuSPL9. a The change in floral organs occurred in the CbuSPL9-overexpressing transgenic Arabidopsis lines. Image of a normal flower from col. as the control (a/l); and the floral organ mutant from oespl9 (a/II-VI). a/II showing shrunken petals (White arrow) and increased stamens (Right arrow); a/III showing loss petal (White arrow); a/IV showing loss petal (White arrow); a/N showing increased petal (White arrow); aNl showing overlapping petals (White arrow) and loss stamens (Right arrow); b Comparison of the flowering phenotype in both the col. and oespl9 transgenic plants. From top to bottom: col. (control) and oespl9 (transgenic plants). Bars = $2 \mathrm{~mm}$ in $(\mathrm{a} / \mathrm{II}-\mathrm{VI}), 1.5 \mathrm{~cm}$ in (b). $\mathbf{c}$ and $\mathbf{d}$ are the statistical data of the time of flower bud emergence and the number of rosette leaves. The oespl9 transgenic plants (black), the oe-hmga transgenic plants (gray) and the col. plants (white). A total of 30 plants were averaged to obtain the mean. Error bars indicate SD

\section{Cloning the $H M G A$ gene}

Among these candidates, HMGA, which is an AT-hook rich protein, belongs to the most abundant nonhistone protein family in the nucleus. We cloned the full-length HMGA homologous gene via rapid amplification of cDNA ends. Phylogenic analysis revealed that this protein has a close relationship with AtHMGA. Therefore, this protein was renamed CbuHMGA. CbuHMGA encoded a H15 domain and 4 AT-hook motifs (Fig. 4a).
The expression analysis showed that the expression trend of CbuHMGA was similar to that of CbuSPL9 in the four periods in "Bairihua" (Fig. 4b). The expression of CbuHMGA was elevated in the dormant period, and the highest expression level was detected in the reproductive growth period. However, the increase in the expression of CbuHMGA before the reproductive growth period occurred slightly earlier than that of CbuSPL9. 
Table 1 Details of the proteins interacting with the CbuSPL9 protein

\begin{tabular}{ll}
\hline Annotation & Quantity \\
\hline Sesamum indicum HMG-Y-related protein B-like (LOC105159884), mRNA & 4 \\
PREDICTED: Sesamum indicum aquaporin PIP2-4-like (LOC105174310), mRNA & 1 \\
PREDICTED: Sesamum indicum GATA transcription factor 8 (LOC105166606), transcript variant X2, mRNA & 1 \\
PREDICTED: Sesamum indicum heavy metal-associated isoprenylated plant protein 33-like (LOC105156967), mRNA & 2 \\
PREDICTED: Sesamum indicum probable E3 ubiquitin ligase SUD1 (LOC105169523), mRNA & 4 \\
PREDICTED: Erythranthe guttatus transcription factor bHLH48-like (LOC105966580), mRNA & 1 \\
PREDICTED: Sesamum indicum aquaporin TIP1-1-like (LOC105170758), mRNA & 1 \\
PREDICTED: Sesamum indicum probable GTP diphosphokinase RSH2, chloroplastic (LOC105157806), transcript variant X1, mRNA & 1 \\
Arabidopsis thaliana proline-rich family protein mRNA ((PRPS) & 1 \\
PREDICTED: Sesamum indicum fasciclin-like arabinogalactan protein 17 (LOC105161692), mRNA & 1 \\
PREDICTED: Erythranthe guttatus MAG2-interacting protein 2 (LOC105963338), mRNA & 1 \\
\hline
\end{tabular}

a

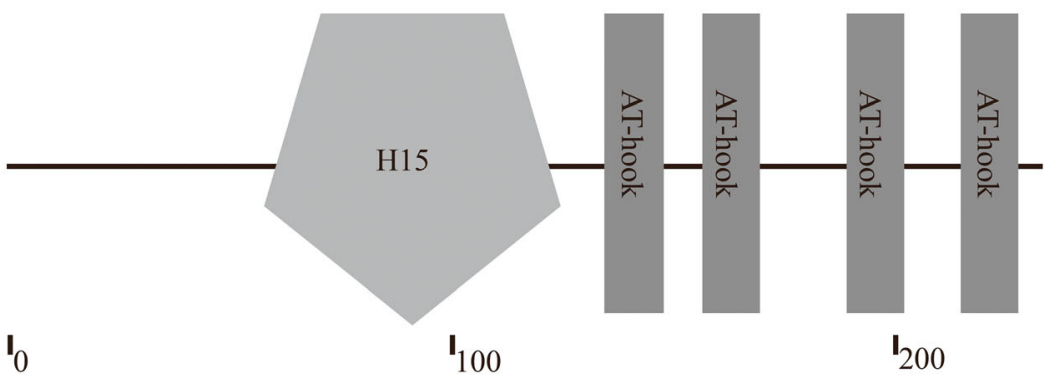

$\mathrm{b}$

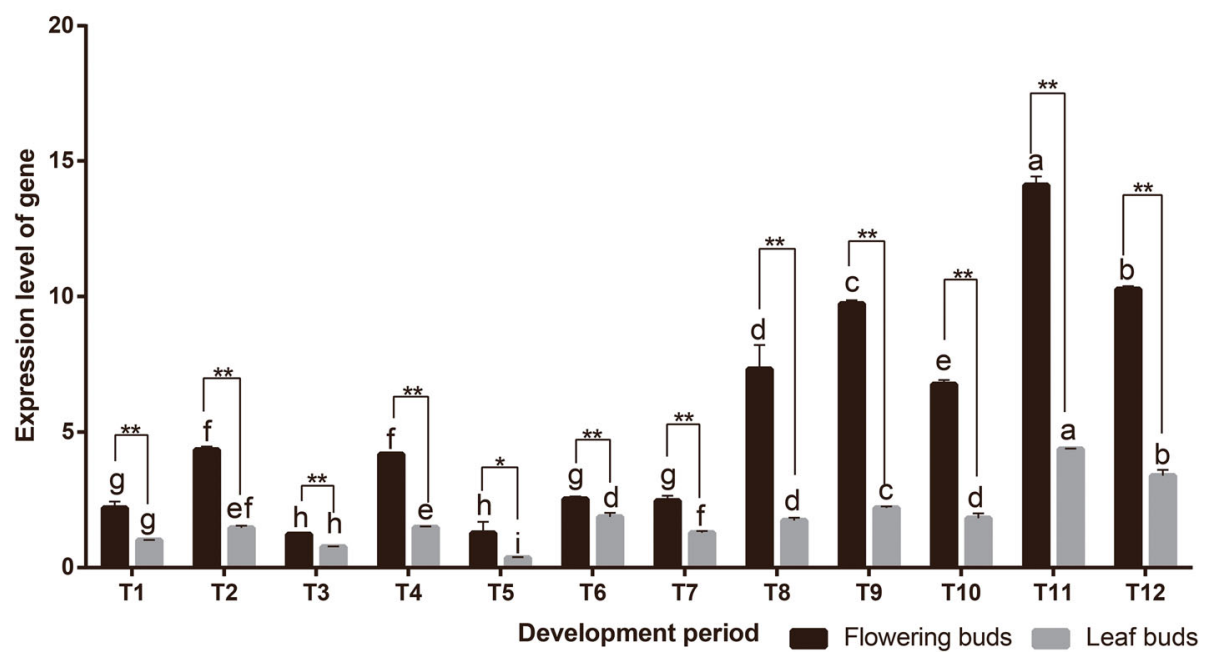

Fig. 4 The sequence and expression profile analysis of CbuHMGA. a Sequence analysis of the CbuHMGA protein by SMART. b The expression analysis of CbuHMGA between flowering buds and leaf buds during the development periods. T1-T3 represents the flowering buds and leaf buds collected in the dormant period; T4-T5 represents the flowering buds and leaf buds collected in the germination period; T6-T9 represents the flowering buds and leaf buds collected in the floral transition period; and T10-T12 represents the flowering buds and leaf buds collected in the reproductive period. Notably, even though floral transition was never observed in the leaf buds, the leaf buds collected in the period corresponding to floral transition are henceforth called the floral transition period and reproductive period for convenience. Error bars indicate SD from three independent experiments. *Difference between flowering buds (black) and leaf buds (gray) is significant (Student's test; $p<0.05$ ). **Difference between flowering buds (black) and leaf buds (gray) is highly significant (Student's test; $p<0.01$ ) 


\section{Localization of the CbuSPL9 and CbuHMGA proteins}

We fused GFP at the C-terminus of CbuSPL9 and CbuHMGA and transformed them into Nicotiana benthamiana leaf epidermal cells to determine the localization of the CbuSPL9 and CbuHMGA proteins. 35S:GFP was used as a control. The GFP fluorescence in CbuSPL9-GFP and CbuHMGA-GFP was exclusively observed in the nucleus, whereas the fluorescence of GFP in the control was distributed throughout the entire cell (Fig. 5a). These results showed that CbuSPL9 and CbuHMGA were located in the nucleus. This result was in agreement with the prediction based on the protein structure.

\section{Protein interaction analysis}

Biolayer interferometry (BLI) [51] was used to determine dissociation constants $\left(\mathrm{K}_{\mathrm{D}}\right)$ as well as the on- and offrate ( $k_{\text {on }}$ and $k_{\text {off }}$ ) for HIS-CbuHMGA binding to GSTCbuSPL9 (Table 2). Five different concentrations of

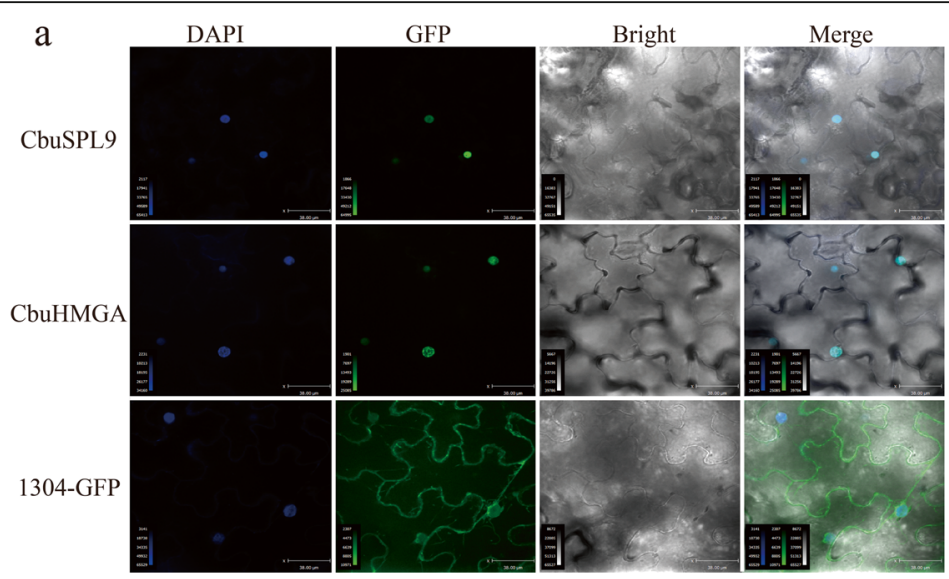

b
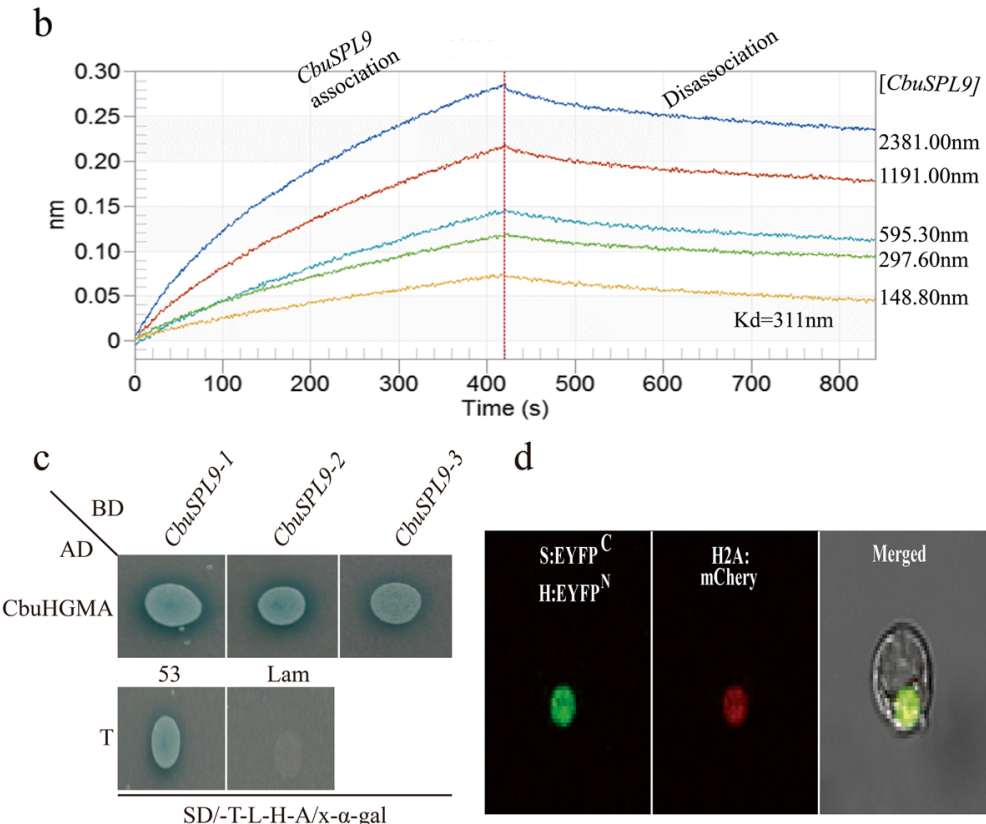

d

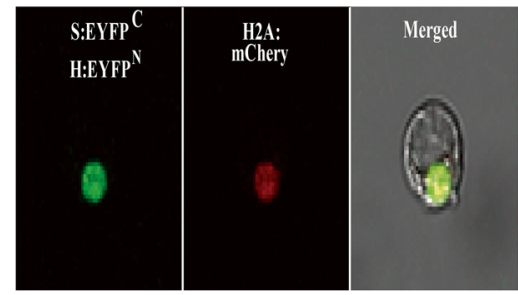

Fig. 5 Interaction between the two proteins CbuSPL9 and CbuHMGA. a Nuclear localization of the CbuSPL9 protein and CbuHMGA protein. The GFP (control) gene, CbuSPL9-GFP fusion gene and CbuHMGA-GFP fusion gene were expressed transiently in Nicotiana benthamiana leaf epidermal cells and observed with confocal microscopy. DAPI, DAPI for nuclear staining image; GFP, GFP green fluorescence image; Merge, the merged images of bright-field, GFP and DAPI staining. b Binding of GST-CbuSPL9 to HIS-CbuHMGA, with GST-CbuSPL9 concentrations of 2381.00 nm, $1191.0 \mathrm{~nm}, 595.30 \mathrm{~nm}, 297.60 \mathrm{~nm}, 148.80 \mathrm{~nm}$ assessed by real-time biolayer interferometry. c Yeast two-hybrid assays for the interactions between CbuSPL9 and CbuHMGA. CbuHMGA (as prey) was fused with the GAL4 activation domain (AD) in pGADT7, while CbuSPL9 (as bait) was fused with the GAL DNA-binding domain (BD) in pGBKT7. The positive control was as follows: pGADT7-T and pGBK-53. The negative control was as follows: pGADT7-T and pGBK-Lam. Interactions are indicated by the blue color on SD/-Trp/-Leu/-His/-Ade/X-a-gal medium. d Confocal images of the BiFC analysis in protoplasts from $P$. trichocarpa. CbuSPL9 was fused with EYFPC, and CbuHMGA was fused with EYFPN . EYFP signal was detected in the nucleus of the S1-21 protoplasts transfected by H2A:mCherry and CbuSPL9:EYFPC with (A) CbuHMGA:EYFPN . Bars = 50 $\mu$ m 
Table 2 Interaction between HIS-CbuHMGA and GST-CbuSPL9 by BLI

\begin{tabular}{|c|c|c|c|c|c|}
\hline Protein 1 & Ptotein2 & Conc. of Protein $2 / n M$ & $\mathrm{~K}_{\mathrm{on}} / \mathrm{Ms}$ & $\mathrm{K}_{\text {off }} / \mathrm{s}$ & $\mathrm{K}_{\mathrm{D}} / \mathrm{nM}$ \\
\hline HIS-CbuHMGA & GST-CbuSPL9 & 2381 & $5.40 \mathrm{E}-04$ & $1.74 \mathrm{E}+03$ & 311 \\
\hline HIS-CbuHMGA & GST-CbuSPL9 & 1191 & $5.40 \mathrm{E}-04$ & $1.74 \mathrm{E}+03$ & 311 \\
\hline HIS-CbuHMGA & GST-CbuSPL9 & 595.3 & $5.40 \mathrm{E}-04$ & $1.74 \mathrm{E}+03$ & 311 \\
\hline HIS-CbuHMGA & GST-CbuSPL9 & 297.6 & $5.40 \mathrm{E}-04$ & $1.74 \mathrm{E}+03$ & 311 \\
\hline HIS-CbuHMGA & GST-CbuSPL9 & 148.8 & 5.40E-04 & $1.74 \mathrm{E}+03$ & 311 \\
\hline
\end{tabular}

GST-CbuSPL9 $(2381.00 \mathrm{~nm}, 1191.00 \mathrm{~nm}, 595.30 \mathrm{~nm}$, 297.60 and $148.80 \mathrm{~nm}$ ) were evaluated, and the $\mathrm{K}_{\mathrm{D}}$ was $311 \mathrm{~nm}$ for each tested concentration. These results suggested a strong interaction between CbuSPL9 and CbuHMGA (Fig. 5b).

To confirm these interactions, the full-length cDNA of CbuSPL9 was inserted into the vector pGBKT7 (BDCbuSPL9) as bait, and the full-length cDNA of CbuHMGA was inserted into the vector pGADT7 (AD-CbuHMGA) as prey. Yeast strains containing AD-CbuHMGA and BDCbuSPL9 were positive for X- $\alpha$-gal activity when grown on synthetically defined (SD)/-Trp/-Leu/-His/-Ade medium (Fig. 5c). These results showed that CbuSPL9 interacted with HMGA in yeast. Finally, a bimolecular fluorescence complementation (BiFC) assay was performed. CbuSPL: EYFP $^{C}$ was cotransfected with CbuHMGA:EYFP ${ }^{N}$ and H2A:mCherry into protoplasts. The signal of enhanced yellow fluorescent protein (EYFP) was colocalized with mCherry (Fig. 5d). Collectively, we demonstrated that CbuSPL9 formed a heterodimer with CbuHMGA in the nucleus.

\section{The overexpression of CbuHMGA in Arabidopsis}

To characterize the potential function of CbuHMGA, we overexpressed CbuHMGA in Arabidopsis. The oe-hmga transgenic lines developed aberrant flowers (Fig. 6aI-VI). This mutant phenotype was similar to the phenotype of floral organs when CbuSPL9 was overexpressed (Additional file 10). However, flowering time was not affected in the oe-hmga transgenic lines compared to that in the col line (Additional file 11). The expression of endogenous AtSPL9 was thoroughly studied to further monitor flower development in the transgenic lines. Within the sampling period, the expression level of AtSPL9 continuously increased in oe-hmga and wild type. However, in oespl9, the expression of AtSPL9 reached a peak in T6 and then decreased (Fig. 6b). The shift in AtSPL9 expression in $o e$-spl9, but not in oe-hmga, further confirmed the observation that CbuHMGA cannot accelerate flower development, while CbuSPL9 can accelerate flower development.

\section{Discussion}

Flowering is a very complex process, a qualitative change in the life history of higher plants, and a central link in plant development. "Bairihua", a variety of the flowering perennial woody plant $C$. bungei, has a large amount of flowers and a long flowering period. "Bairihua" is an excellent material for evaluating the flowering process in trees.

SPLs play an important role in regulating flowering in many plants, most notably in Arabidopsis. In woody plants, SPLs are studied extensively, but limited information about flowering is known [25, 26, 28, 52, 53]. Here, we cloned the SBP-domain-encoding gene CbuSPL9 in C. bungei. Its conserved structure, flower developmentrelated expression trend and the correlations with miR156, CbuAP1 and CbuLeafy suggest that CbuSPL9 might have conserved SPL9 functions in C. bungei. Furthermore, heterogeneous overexpression of CbuSPL9 in Arabidopsis accelerated flower development and lead to aberrant flower organs.

TFs can affect biological processes by forming complexes with other TFs. However, most of the studies on SPLs have focused on their interactions with DNA motifs [36-38]. The proteins that could directly interact with SPLs and participate in flower regulation are largely unknown. For further insight, we screened the yeast hybridization library for CbuSPL9 in buds. Many flowering-related proteins were detected, for example, the GATA-related proteins [54-57], bHLH48 [58], FLA [59], and PHD finger protein ALFIN-LIKE [60]. Furthermore, a high mobility group (HMG) protein, CbuHMGA, was identified to interact directly with CbuSPL9. The BiFC assay and BLI assay further confirmed their interaction. The BiFC assay suggested that CbuSPL9 and CbuHMGA could form protein complexes in the nucleus.

ChuHMGA contains an H15 domain and 4 AT-hook motifs. This similar structural description was confirmed in most plant HMGA proteins, which encoded four four AT-hook motifs $[61,62]$. Additionally, the amino-terminal region of plant HMGA proteins shares remarkable homology with the DNA-binding domain of histone $\mathrm{H} 1$ $[63,64]$. ChuHMGA proteins have a highly conserved structure. HMGA is an architectural TF [65-67]. It regulates gene expression in vivo by controlling the formation of multiprotein complexes on the AT-rich regions of certain gene promoters [63, 64, 66, 68, 69]. To date, some plant HMGA proteins have been isolated, such as those in soybean, rice, maize and Arabidopsis [70-75]. And the AT-hook motif has also been reported that AT-hook 
a

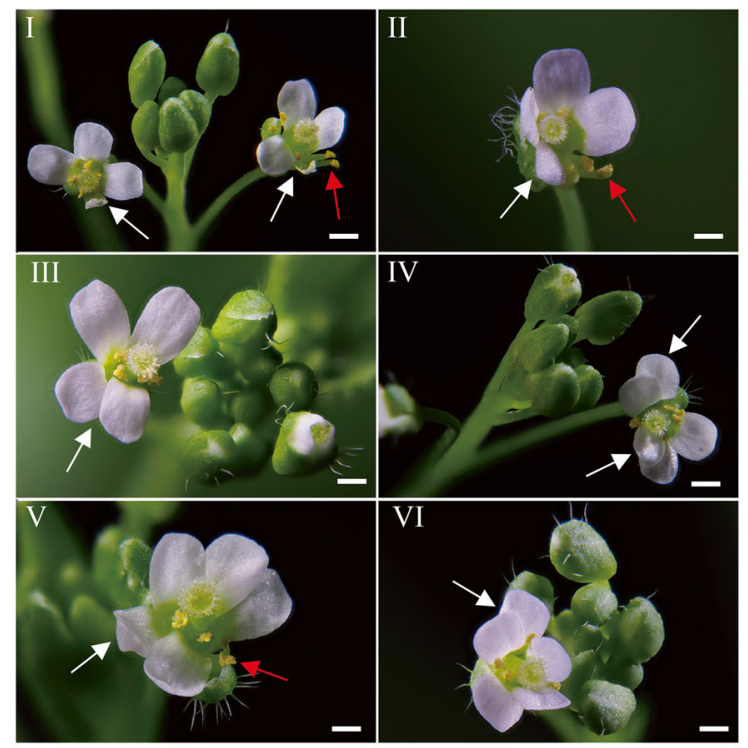

$\mathrm{b}$

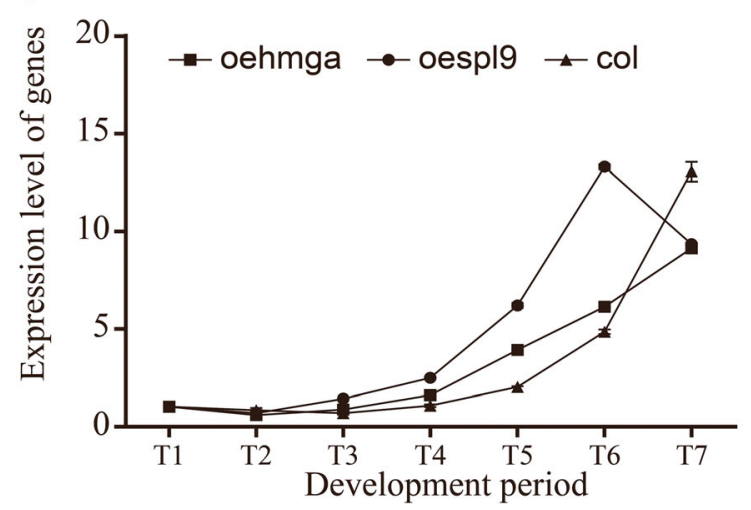

Fig. 6 Phenotype of overexpression mutants of CbuHMGA. a The change in floral organs occurred in the overexpression of the CbuHMGA transgenic Arabidopsis lines. The images are the floral organ mutant from oe-hmga transgenic Arabidopsis lines (a/I-VI). a/l showing shrunken petals (White arrow); a/ll showing dislocation petals (White arrow) and separating stamens (Red arrow); a/lll showing dislocation petals (White arrow); a/IV showing overlapping petals (White arrow); aN showing increased petal (White arrow) and loss stamens (Red arrow); a/VI showing increased petals (White arrow); Bars $=2 \mathrm{~mm}$ in (a/I-VI). b Expression profiles of atSPL9 homologous genes in the oespl9 transgenic plants, oehmga transgenic plants and col. $\longrightarrow$ - represents the PCR results in oe-hmga; $\boldsymbol{\longrightarrow}$ - represents the PCR results in oespl9; and $\longrightarrow-$ represents the PCR results in col. Three independent biological replicates were performed, and each replicate was measured in triplicate. The error bars show the standard deviation of the results of three technical replicates

proteins also affects the flowering process [71, 75, 76]. However, studies of the interacting proteins and the function of HMGA in woody plants are rare. In "Bairihua", the expression of CbuHMGA was elevated in the dormant period, and the highest expression level was detected in the reproductive growth period. The result was consistent with that in Arabidopsis. Although the oe-hmga transgenic lines did not show a flowering time phenotype, the floral organ mutation of oe-hmga was similar to that of the oe-sply transgenic lines.

The HMGA proteins have an important role in biological processes and interact with different TFs [66, 67]. Their intrinsic flexibility allows the HMGA proteins to participate in specific protein-DNA and protein-protein interactions that induce structural changes in chromatin and the formation of stereospecific complexes called 'enhanceosomes' on the promoter/enhancer regions of genes whose transcription they regulate. The chromatin structure changes affect the ability of TFs to bind with the promoter/enhancer regions [61, 70, 76-79]. From the results in this study, we suggest that the interaction of CbuHMGA with CbuSPL9 might strengthen or weaken the binding ability of CbuSPL9 with the corresponding DNA sequences or downstream proteins, thus affecting the flowering process. Further experiments are needed to test this hypothesis. For example, overexpression one gene 
in an other gene Arabidopsis mutant, to reveal pstream and downstream relationship of CbuSPL9 interacting with CbuHMGA during flowering in Caltalpa bungei.

\section{Conclusion}

"Bairihua" provides us with a valuable opportunity to gain a deeper understanding of the flowering process of woody plants. Our study showed that SPLS may have similar structures and regulatory mechanisms in perennial trees and Arabidopsis. Screening CbuSPL9-interacting proteins revealed not only additional proteins for research on the regulatory pathway of CbuSPL9 but also the CbuSPL9 interaction with CbuHMGA. oe-hmga showed a phenotype that affected floral organ development but did not change flowering time. This result suggests that the mechanism by which CbuSPL9 affects the flowering process is a complex process, and CbuHMGA is involved in the development of flower organs but not in the regulation of flowering time.

\section{Supplementary information}

Supplementary information accompanies this paper at https://doi.org/10. 1186/s12870-020-2303-z.

Additional file 1: Table S1. The list of the all Primers used in this paper.

Additional file 2: Figure S1. Verification of oe-SPL9 positive Arabidopsis.

Additional file 3: Figure S2. Verification of oe-HMGA positive Arabidopsis.

Additional file 4: Table S2. Details of motif-sequences of CbuSPL9 were identified by MEME.

Additional file 5: Tables S3. Details of CDUSPL9 was predicted to be a target of miR156.

Additional file 6: Figure S3. Expression profile of miR156 in the flower buds and leaf buds during the developmental periods of $C$. bungei.

Additional file 7: Figure S4. Expression profile of CbuLeafy and CbuAP1 in the flower buds and leaf buds during the developmental periods of $C$. bungei.

Additional file 8: Table S4. Statistics of mutant of floral organs in oeSPL9 Arabidopsis.

Additional file 9: Table S5. Statistics of mutant of flowering time in oeSPL9 Arabidopsis.

Additional file 10: Table S6. Statistics of mutant of floral organs in oeHMGA Arabidopsis.

Additional file 11: Table S7. Statistics of mutant of flowering time in oe-HMGA Arabidopsis.

\section{Acknowledgments}

We appreciate Chinese Academy of Forestry for providing plant materials; We would like to thank the laboratory for participating in the study; We acknowledge the anonymous referees for their constructive comments on the paper, which have greatly improved its.

\section{Authors' contributions}

JHW, SGZ, GZQ, LIS, ZW and WJM designed the experiments. ZW and WJM analyzed the RNA-seq data and wrote the manuscript. ZW, FEQ, and TQZ detected the expression of genes using GRT-PCR. ZW, NL, FQOY, NW and GJY collected the samples used in the experiment. All the authors have read the paper and agreed to list their names as co-authors. The author(s) read and approved the final manuscript.

\section{Funding}

This work was supported by Fundamental Research Funds of Chinese Academy of Forestry (CAFYBB2017ZY002); Fundamental Research Funds of Chinese Academy of Forestry (CAFYBB2017ZA001-8). The funders had no role in the study design, data analysis and interpretation, and manuscript writing, but just provided the financial.

\section{Availability of data and materials}

The data that supporting the conclusions of the article have been uploaded as additional files.

\section{Ethics approval and consent to participate}

This article does not contain any studies with human participants or animals performed by any of the authors. All the plant materials used in this study were provided by Research Institute of Forestry, Chinese Academy of Forestry. The field experiments were conducted under local legislation and permissions.

\section{Consent for publication}

Not applicable.

\section{Competing interests}

The authors declare that they have no competing interests.

\section{Author details}

${ }^{1}$ Present address: State Key Laboratory of Tree Genetics and Breeding, Key Laboratory of Tree Breeding and Cultivation of State Forestry Administration, Research Institute of Forestry, Chinese Academy of Forestry, Beijing 100091, People's Republic of China. ${ }^{2}$ Present address: Department of Biology Centre for Forest Biology, University of Victoria, Victoria 11, BC, Canada. ${ }^{3}$ Present address: State Key Laboratory of Tree Genetics and Breeding, Northeast Forestry University, 26 Hexing Road, Harbin 150040, People's Republic of China.

Received: 9 November 2019 Accepted: 24 February 2020

Published online: 06 March 2020

\section{References}

1. Jing D, Xia Y, Chen F, Wang Z, Zhang S, Wang J. Ectopic expression of a Catalpa bungei (Bignoniaceae) PISTILLATA homologue rescues the petal and stamen identities in Arabidopsis pi-1 mutant. Plant Sci. 2015;231:40-51. https://doi.org/10.1016/j.plantsci.2014.11.004.

2. Mouradov A, Cremer F, Coupland G. Control of flowering time: interacting pathways as a basis for diversity. Plant Cell. 2002;14(Suppl):S111-30.

3. Flowers JM, Hanzawa Y, Hall MC, Moore RC, Purugganan MD. Population genomics of the arabidopsis thaliana flowering time gene network. Mol Biol Evol. 2009;26:2475-86.

4. Fornara F, de Montaigu A, Coupland G. SnapShot: control of flowering in arabidopsis. Cell. 2010;141:3-5.

5. Bouché F, Lobet G, Tocquin P, Périlleux C. FLOR-ID: An interactive database of flowering-time gene networks in Arabidopsis thaliana. Nucleic Acids Res. 2016;44:D1167-71

6. Wang J. Regulation of flowering time by the miR156-mediated age pathway. J Exp Bot. 2014;65:4723-7430.

7. Eriksson S. GA4 is the active gibberellin in the regulation of LEAFY transcription and Arabidopsis floral initiation. Plant Cell Online. 2006;18: 2172-81. https://doi.org/10.1105/tpc.106.042317.

8. Livne S, Lor VS, Nir I, Eliaz N, Aharoni A, Olszewski NE, et al. Uncovering DELLA-independent gibberellin responses by characterizing new tomato procera mutants. Plant Cell. 2015;27:1579-94.

9. Cao D, Cheng H, Wu W, Soo HM, Peng J. Gibberellin mobilizes distinct DELLA-dependent Transcriptomes to regulate seed germination and floral development in Arabidopsis. Plant Physiol. 2006;142:509-25.

10. Yu S, Galvao VC, Zhang Y-C, Horrer D, Zhang T-Q, Hao Y-H, et al. Gibberellin regulates the Arabidopsis floral transition through miR156-targeted SQUAMOSA PROMOTER BINDING-LIKE transcription factors. Plant Cell. 2012; 24:3320-32. https://doi.org/10.1105/tpc.112.101014. 
11. Matsubara K, Ogiso-tanaka E, Hori K, Ebana K, Ando T, Yano M. Natural variation in Hd17, a Homolog of Arabidopsis ELF3 That is Involved in Rice Photoperiodic Flowering. Plant Cell Physiol. 2017:53:709-16.

12. Wang H, Pan J, Li Y, Lou D, Hu Y, Yu D. The DELLA-CONSTANS Transcription Factor Cascade Integrates Gibberellic Acid and Photoperiod Signaling to Regulate Flowering. Plant Physiol. 2016;172(September):479-88.

13. Cano B, Ruiz MT, Romero JM, Valverde F. Photoperiodic control of carbon distribution during the floral transition in Arabidopsis. Plant Cell. 2014;26: 565-84.

14. Heo JB, Sung S. Vernalization-mediated epigenetic silencing by a long intronic noncoding RNA. Science. 2011;331:76.

15. Kim DH, Sung S. Coordination of the vernalization response through a VIN3 and FLC gene family regulatory network in Arabidopsis. Plant Cell. 2013;25: 454-69

16. Huang B, Qian P, Gao N, Shen J, Hou S. Fackel interacts with gibberellic acid signaling and vernalization to mediate flowering in Arabidopsis. Planta. 2017;245:939-50.

17. Simpson GG. The autonomous pathway: epigenetic and post-transcriptional gene regulation in the control of Arabidopsis flowering time. Curr Opin Plant Biol. 2004;7:570-4.

18. Unte US. SPL8, an SBP-box gene that affects pollen sac development in Arabidopsis. Plant Cell Online. 2003;15:1009-19.

19. Preston JC, Hileman LC. Functional Evolution in the Plant SQUAMOSAPROMOTER BINDING PROTEIN-LIKE (SPL) Gene Family. Front Plant Sci. 2013; 4(April):1-13. https://doi.org/10.3389/fpls.2013.00080.

20. Jung JH, Lee HJ, Ryu JY, Park CM. SPL3/4/5 integrate developmental aging and photoperiodic signals into the FT-FD module in Arabidopsis flowering Mol Plant. 2016;9:1647-59. https://doi.org/10.1016/j.molp.2016.10.014.

21. Casero D, Singh V, Wilson GT, Grande A, Yang H, Dodani SC, et al. Transcriptome sequencing identifies SPL7-regulated copper acquisition genes FRO4/FRO5 and the copper dependence of Iron homeostasis in Arabidopsis. Plant Cell Online. 2012;24:738-61.

22. Yu N, Niu QW, Ng KH, Chua NH. The role of miR156/SPLs modules in Arabidopsis lateral root development. Plant J. 2015;83:673-85.

23. Zhang $X$, Dou L, Pang C, Song M, Wei H, Fan S. Genomic organization, differential expression, and functional analysis of the SPL gene family in Gossypium hirsutum. Mol Gen Genomics. 2015;290:115-26.

24. De Mao H, Yu LJ, Li ZJ, Yan Y, Han R, Liu H, et al. Genome-wide analysis of the SPL family transcription factors and their responses to abiotic stresses in maize. Plant Gene. 2016;6:1-12. https://doi.org/10.1016/j.plgene.2016.03.003.

25. Lannenpaa M, Janonen I, Sopanen T, Porali I, Gardemeister M, Holtta-Vuori M. A new SBP-box gene BPSPL1 in silver birch (Betula pendula). Physiol Plant. 2004;120:491-500.

26. Xu Z, Sun L, Zhou Y, Yang W, Cheng T, Wang J, et al. Identification and expression analysis of the SQUAMOSA promoter-binding protein (SBP)-box gene family in Prunus mume. Mol Gen Genomics. 2015;290:1701-15.

27. Han H, Liu G, Zhang J, Zhang S, Cai F, Bao Z, et al. Four SQUAMOSA PROMOTER BINDING PROTEIN-LIKE homologs from a basal eudicot tree (Platanus acerifolia) show diverse expression pattern and ability of inducing early flowering in Arabidopsis. Trees - Struct Funct. 2016;30:1417-28.

28. Li C, Lu S. Molecular characterization of the SPL gene family in Populus trichocarpa. BMC Plant Biol. 2014;14:131.

29. Xing S, Salinas M, Garcia-Molina A, Höhmann S, Berndtgen R, Huijser P. SPL8 and miR156-targeted SPL genes redundantly regulate Arabidopsis gynoecium differential patterning. Plant J. 2013;75:566-77.

30. Xing S, Salinas M, Höhmann S, Berndtgen R, Huijser P. miR156-Targeted and Nontargeted SBP-Box Transcription Factors Act in Concert to Secure Male Fertility in Arabidopsis. Plant Cell. 2010;22:3935-50.

31. Yan J, Chia J-C, Sheng H, Jung H, Zavodna T-O, Lu Z, et al. Arabidopsis Pollen Fertility Requires the Transcription Factors CIT1 and SPL7 that Regulate Copper Delivery to Anthers and Jasmonic Acid Synthesis. Plant Cell. 2017. https://doi.org/10.1105/tpc.17.00363 tpc.00363.2017.

32. Yamasaki H, Hayashi M, Fukazawa M, Kobayashi Y, Shikanai T. SQUAMOSA promoter binding protein-Like7 is a central regulator for copper homeostasis in Arabidopsis. Plant Cell Online. 2009;21:347-61. https://doi. org/10.1105/tpc.108.060137.

33. Hyun Y, Richter R, Coupland G. Competence to flower: age-controlled sensitivity to environmental cues. Plant Physiol. 2017;173:36-46.

34. Poethig RS. Vegetative phase change and shoot maturation in plants. Curr Top Dev Biol. 2013;105:125-52. https://doi.org/10.1016/B978-0-12-396968-2. 00005-1.
35. Yu N, Cai WJ, Wang S, Shan CM, Wang LJ, Chen XY. Temporal control of trichome distribution by microRNA156-targeted SPL genes in Arabidopsis thaliana. Plant Cell. 2010;22(7):2322-35.

36. Yamaguchi A, Wu M-F, Yang L, Wu G, Poethig RS, Wagner D. The microRNA regulated SBP-box transcription factor SPL3 is a direct upstream activator of LEAFY, FRUITFULL, and APETALA1. Dev Cell. 2010;17:268-78.

37. Wang J, Czech B, Weigel D. miR156-Regulated SPL Transcription Factors Define an Endogenous Flowering Pathway in Arabidopsis thaliana. Cell. 2009:138:738-49.

38. Wu G, Poethig RS. Temporal regulation of shoot development in Arabidopsis thaliana by miRr156 and its target SPL3. Development. 2006; 133:3539-47.

39. Xie XB, Li S, Zhang RF, Zhao J, Chen YC, Zhao Q, et al. The bHLH transcription factor MdbHLH3 promotes anthocyanin accumulation and fruit colouration in response to low temperature in apples. Plant Cell Environ. 2012;35:1884-97.

40. An XH, Tian Y, Chen KQ, Liu XJ, Liu DD, Xie XB, et al. MdMYB9 and MdMYB11 are involved in the regulation of the ja-induced biosynthesis of anthocyanin and proanthocyanidin in apples. Plant Cell Physiol. 2015;56:650-62.

41. Qi T, Song S, Ren Q, Wu D, Huang H, Chen Y, et al. The Jasmonate-ZIMdomain proteins interact with the WD-repeat/bHLH/MYB complexes to regulate Jasmonate-mediated anthocyanin accumulation and Trichome initiation in Arabidopsis thaliana. Plant Cell. 2011;23:1795-814.

42. Zhou J, Wang X, Lee J-Y, Lee J-Y. Cell-to-cell movement of two interacting AT-hook factors in Arabidopsis root vascular tissue patterning. Plant Cell. 2013:25:187-201.

43. Shu W, Liu Y, Guo Y, Zhou H, Zhang J, Zhao S. A Populus TIR1 gene family survey reveals differential expression patterns and responses to 1naphthaleneacetic acid and stress treatments. Front Plant Sci. 2015; 6(September):1-10.

44. Wang Z, Zhu T, Ma W, Wang N, Qu G, Zhang S, et al. Genome-wide analysis of long non-coding RNAs in Catalpa bungei and their potential function in floral transition using high-throughput sequencing. BMC Genet. 2018;19:1-16.

45. Kang C, Liu Z. Global identification and analysis of long non-coding RNAs in diploid strawberry Fragaria vesca during flower and fruit development. BMC Genomics. 2015;16:1-15. https://doi.org/10.1186/s12864-015-2014-2.

46. Jung J, Seo Y, Seo PJ, Reyes JL, Yun J, Chua N, et al. The GIGANTEA -Regulated MicroRNA172 Mediates Photoperiodic Flowering Independent of CONSTANS in Arabidopsis. Plant Cell. 2007;19(September):2736-48.

47. Kotchoni SO, Larrimore KE, Mukherjee M, Kempinski CF, Barth C, Virginia W. Alterations in the Endogenous Ascorbic Acid Content Affect Flowering Time in Arabidopsis. Plant Physiol. 2009;149(February):803-15.

48. Zhang S, Ling L. Evolution and divergence of SBP-box genes in land plants. BMC Genomics. 2015;16:787

49. Yu S, Lian H, Wang JW. Plant developmental transitions: the role of microRNAs and sugars. Curr Opin Plant Biol. 2015;27:1-7. https://doi.org/10. 1016/j.pbi.2015.05.009.

50. Wang JW, Mee YP, Wang $\sqcup$, Yeonjong K, Chen XY, Detlef W, Poethig RS. miRNA control of vegetative phase change in trees. PLoS Genet. 2011;7(2):e1002012.

51. Zhang Y, Mao D, Roswit WT, Jin X, Patel AC, Patel DA, et al. PARP9-DTX3L ubiquitin ligase targets host histone $\mathrm{H} 2 \mathrm{BJ}$ and viral $3 \mathrm{C}$ protease to enhance interferon signaling and control viral infection. Nat Immunol. 2015;16:121527. https://doi.org/10.1038/ni.3279.

52. Castillo MC, Forment J, Gadea J, Carrasco JL, Juarez J, Navarro L, et al. Identification of transcription factors potentially involved in the juvenile to adult phase transition in citrus. Ann Bot. 2013;112:1371-81.

53. Tewari S, Buonaccorsi JP. Impact of early season apical meristem injury by gall inducing Tipworm (Diptera: Cecidomyiidae) on reproductive and vegetative growth of cranberry entomology. J Econ Entomol. 2013;106:1339-48.

54. Mara CD, Irish VF. Two GATA transcription factors are downstream effectors of floral homeotic gene action in Arabidopsis. Plant Physiol. 2008;147:70718. https://doi.org/10.1104/pp.107.115634.

55. Ding L, Yan S, Jiang L, Liu M, Zhang J, Zhao J, et al. HANABA TARANU regulates the shoot apical meristem and leaf development in cucumber (Cucumis sativus L.). J Exp Bot. 2015;66:7075-87.

56. Ding $L$, Yan $S$, Jiang $L$, Zhao W, Ning $K$, Zhao J, et al. HANABA TARANU (HAN) bridges meristem and organ Primordia boundaries through PINHEAD, JAGGED, BLADE-ON-PETIOLE2 and CYTOKININ OXIDASE 3 during flower development in Arabidopsis. PLoS Genet. 2015;11:1-23.

57. Zhang $X$, Zhou Y, Ding L, Wu Z, Liu R, Meyerowitz EM. Transcription repressor HANABA TARANU controls flower development by integrating the 
actions of multiple hormones, floral organ specification genes, and GATA3 family genes in Arabidopsis. Plant Cell. 2013;25:83-101.

58. Li Y, Wang H, Li X, Liang G, Yu D. Two DELLA-interacting proteins bHLH48 and bHLH60 regulate flowering under long-day conditions in Arabidopsis thaliana. J Exp Bot. 2017;68:2757-67.

59. Li J, Yu M, Geng LL, Zhao J. The fasciclin-like arabinogalactan protein gene, FLA3, is involved in microspore development of Arabidopsis. Plant J. 2010; 64:482-97.

60. Pan W-J, Zhang J-S, Tao J-J, Lu L, Ma B, Li Q-T, et al. An Alfin-like gene from Atriplex hortensis enhances salt and drought tolerance and abscisic acid response in transgenic Arabidopsis. Sci Rep. 2018;8:1-13. https://doi.org/10. 1038/s41598-018-21148-9.

61. Dragan Al, Liggins JR, Crane-Robinson C, Privalov PL. The energetics of specific binding of AT-hooks from HMGA1 to target DNA. J Mol Biol. 2003; 327:393-411.

62. Klosterman SJ, Hadwiger LA. Plant HMG proteins bearing the AT-hook motif. Plant Sci. 2002;162:855-66.

63. Krech AB, Wulff D, Grasser KD, Feix G. Plant chromosomal HMGI/Y proteins and histone $\mathrm{H} 1$ exhibit a protein domain of common origin. Gene. 1999;230:1-5.

64. Reeves R. Molecular biology of HMGA proteins : hubs of nuclear function. Gene. 2001;277:63-81.

65. Reeves R, Beckerbauer L. HMGI/Y proteins:fexible regulators of transcription and chromatin structure. Biochim Biophys Acta. 2001;1519:13-29.

66. Sgarra R, Zammitti S, Lo Sardo A, Maurizio E, Arnoldo L, Pegoraro S, et al. HMGA molecular network: from transcriptional regulation to chromatin remodeling. Biochim Biophys Acta. 1799;2010:37-47.

67. Tessari MA, Gostissa M, Altamur S, Sgarra R, Rustighi A, Salvagno C, Caretti G, Imbriano C, Mantovani R, Del Sal G, Giancotti V, Manfioletti G. Transcriptional activation of the Cyclin a gene by the architectura transcription factor HMGA2. Mol Cell Biol. 2004;23:9104-16.

68. Reeves R, Beckerbauer L. HMGI/Y proteins: flexible regulators of transcription and chromatin structure. Biochim Biophys Acta. 2001;1519:13-29.

69. Gupta R, Webster Cl, Gray JC. The single-copy gene encoding high-mobilitygroup protein HMG-1/Y from pea contains a single intron and is expressed in all organs. Plant Mol Biol. 1997;35:987-92.

70. Pierantoni GM, Rinaldo C, Esposito F, Mottolese M, Soddu S, Fusco A. High mobility group A1 (HMGA1) proteins interact with p53 and inhibit its apoptotic activity. Cell Death Differ. 2006;13:1554-63.

71. Xiao C, Chen F, Yu X, Lin C, Fu YF. Over-expression of an AT-hook gene, AHL22, delays flowering and inhibits the elongation of the hypocotyl in Arabidopsis thaliana. Plant Mol Biol. 2009;71:39-50.

72. Zhao J, Paul LK, Grafi G. The maize HMGA protein is localized to the nucleolus and can be acetylated in vitro at its globular domain, and phosphorylation by CDK reduces its binding activity to AT-rich DNA. Biochim Biophys Acta. 1789;2009:751-7.

73. Laux T, Seurinck J, Goldberg RB. A soybean embryo cDNA encodes a DNA binding protein with histone and HMG-protein-like domains. Nucleic Acids Res. 1991;19:4768

74. Yamamoto S, Minamikawa T. Two genes for the high mobility group protein HMG-Y are present in the genome of Canavalia gladiata D.C. Plant Mol Biol. 1997;33:537-44

75. Cho JH, Kim MJ, Kim KJ, Kim J. POZ / BTB and AT-hook-containing zinc finger protein 1 ( PATZ1) inhibits endothelial cell senescence through a p53 dependent pathway. Cell Death Differ. 2011;19:703-12. https:/doi.org/ 10.1038/cdd.2011.142.

76. Matsushita A, Furumoto T, Ishida S, Takahashi Y. AGF1, an AT-hook protein, is necessary for the negative feedback of AtGA3ox1 encoding GA 3-Oxidase. Plant Physiol. 2007;143:1152-62.

77. Norseen J, Thomae A, Sridharan V, Aiyar A, Schepers A, Lieberman PM. RNAdependent recruitment of the origin recognition complex. EMBO J. 2008;27: 3024-35.

78. Richter T, Mu TE, Heinkele G, Tatzel S, Schwab M, Eichelbaum M, et al. Interaction between HMGA1a and the origin recognition complex creates sitespecific replication origins. PNAS. 2005;308:1-24. https://doi.org/10.1240/sav.

79. Gonzalez N, Pauwels L, Baekelandt A, De Milde L, Van Leene J, Besbrugge N, et al. A repressor protein complex regulates leaf growth in Arabidopsis. Plant Cell. 2015;27:2273-87.

\section{Publisher's Note}

Springer Nature remains neutral with regard to jurisdictional claims in published maps and institutional affiliations.

Ready to submit your research? Choose BMC and benefit from:

- fast, convenient online submission

- thorough peer review by experienced researchers in your field

- rapid publication on acceptance

- support for research data, including large and complex data types

- gold Open Access which fosters wider collaboration and increased citations

- maximum visibility for your research: over $100 \mathrm{M}$ website views per year

At $\mathrm{BMC}$, research is always in progress.

Learn more biomedcentral.com/submissions 